\title{
ICT Literacy and Readiness in Using Computers among Headteachers in their Tertiary Learning Experiences and School Management Tasks
}

\author{
http://dx.doi.org/10.3991/ijet.v10i2.4405 \\ Lokman Mohd Tahir, Mohd Fadzli Ali, Mohd Nihra Haruzuan Mohd Said, and \\ Megat Aman Zahiri Megat Zakaria \\ Universiti Teknologi Malaysia, Malaysia
}

\begin{abstract}
Headteachers are considered as the most influential role in teaching and learning using ICT (Internet, Communication and Technology) in the school setting. Numerous scholars emphasised that as school leaders, they are also competent with technology and computer as part of supporting role model in technological leadership and stewardship. Nevertheless, there is remarkably little research that investigates headteachers' perceptions towards their learning process using ICT. This exploratory research is an attempt to gather data on headteachers' readiness, attachment and their perception of the computer assisted learning process. As for the methodology, ten headteacherss were purposely selected and interviewed in order to address the three essential research questions which were their readiness of using computer; their attachment with computers and their perceptions of teaching and learning using computers in schools. Ten headteachers that were selected as subjects were undergraduate students who are currently enrolling in educational administration and leadership degree in a public university. Findings reveals that headteachers have positive remarks towards the usage of computer in their learning process since the utilization of computers will expose them to the relevant information which helps them as role model for technological stewardship. Secondly, most of headteachers are significantly ready in their learning process using computers and they also felt learning using computers give much opportunities in networking and connecting to other headteachers at other districts.
\end{abstract}

Index Terms—headship; ICT literate and computers.

\section{INTRODUCTION}

It is the policy of the Malaysian government to emphasis on the usage of ICT to create impetus among educational communities in the learning approach for $21^{\text {st }}$ century learning [26]. Without doubt, school leaders influence the ICT practices and developments which embedded into students' learning process and experiences of staffs and teachers $[1,29]$. In general, headteachers are considered as role model in applying and using technology for the purpose of administrative and managerial tasks. At the same time, headteachers should play the role as instructional leaders which facilitate integration and adaption of internet, computer and technology in the classroom teaching and learning processes. Therefore, in supporting and inspiring the usage of computer technology in schools, it is assumed that headteachers are most capable to play essential roles as the technological and instructional leader which facilitates the wide usage of computers for teaching and learning purposes and instructional purposes as well as for school administrative and management tasks. As technology leader, previous researcher [7] believed that headteachers should be an advocacy for technology enhancement in learning and also acquire high competency related to adaptation of ICT in pedagogical element. Therefore, as school leaders, their role is not just to provide ICT facilities but also teach teachers on how to used, adapt and integrate technology in their teaching sessions.

In relation to the role of ICT in school management, researchers $[9,10]$ believed that ICT plays pivotal role in helping headteachers in dealing with their leadership and management roles such as reducing operational costs, improving administration decision making and compensations tasks and roles. In addition, they also believed that ICT also provided information storage medium with regards to school compensations and managerial efficiencies. As ICT catalyst and leader, [6] believed that ICT furnished meaningful tool for managing information for school improvement evidences and storing of teachers and staffs' information which is indispensible for their promotion and career paths. Therefore, as school leaders, headteacher should nurture significant ICT vision which enables the inculcation of ICT integration across curriculum boundaries within and beyond school context. Without doubt, headteachers should provide more opportunities for ICT usage among teachers and staffs for educational purposes and human resources information storage with the assistance of ICT (Ong \& Lay, 2006). Lastly, as an ICT catalyst, headteachers also should adapt themselves to be learner of ICT in order to improve their level of knowledge and provide more understanding of the meaningful usage of ICT.

Significantly, headteachers roles as technological and instructional leader are considered crucial for the supporting efforts of computer utilisation in school context. Davies (2002) [12] posited that the successful and pro-active usage of ICT in schools rests on the level of acceptance to technology by school leaders. Therefore, as an ICT leader, they have high responsibilities to encourage, support and appreciate teachers and students in technology integration within school operational system even creating an innovative culture in schools [28]. Persaud (2006) [13] also emphasised that the integration process between ICT and school leadership involved a paradigm shift in the headteachers ways of thinking. The paradigm shift re- 
quires headteachers to be pro-active leader to develop ICT literacy, lead the technological change and assume the role model of ICT among educational leaders. However, there exists little information in relation to headteachers level of literacy in basic computer operations [4] to the extent related to their readiness, perceptions and willingness in the usage of computers [3]. Therefore, this study is an attempt to fill the gap based on the assumption that headteachers knowledge, perceptions and willingness to support the usage of computer technology is able to enhance the utilisation of computer technology in school as a whole.

\section{LITERATURE REVIEW}

\section{A. ICT and Headteachers}

With the information technology development, computers are important tools for improving the quality of education including the administration of the school [30]. However, based on their research, Maurizio and Wilson (2004) [21] noted that the exposure of using computer technology was limited in developing countries since most of school communities have least experiences and were never trained. Therefore, little experience on ICT remains as barrier for $21^{\text {st }}$ century learning strategies, skills and approaches [14]. Evidently, they acquired very limited knowledge and skills of computer usage which applicable for teaching and learning. They only engaged with a brief in-service courses related to computer technology utilisation. In addition, Okayo (2013) [4] also reported that some school leaders are reluctant to give plenty of support and also harbour negative perceptions on the utilisation of computer technology. It was perceived that the usage computer in classrooms required high skills technical staffs to operate; this entailed the increase of the school's operational costs and minimum of usage for teaching and learning among teachers. Earlier, Yushau (2006) [8] believed that the negative perceptions among senior educated academician and administrators typically originated from lack of computer usage experiences during their early tertiary education. In addition, Krisch and Lennon (2005) [15] emphasis that older workers have problems related to ICT integration since most of them were educated and trained without any assistance from ICT or computer technology. As a consequence, ICT was considered as new skill and the workers are faced with problem working with computers. As for school administrators, negative perception towards the usage of computers derived from lack of engagement with computer courses and training. In addition, the usage of technology in school operations and management tasks were considered as limited. Consequently, headteachers have negative perceptions and also perceived computer technologies as unimportant to school improvement and development processes.

As technology leaders, Malaysian headteachers should be equipped with knowledge related to computer technology and their supporting roles in classroom teaching using ICT. However, most studies pointed that headteachers are unaware of their roles as technology leaders since most of them are unprepared to accept the role of technology leadership. Moreover, a study conducted by Ouya and Mweseli (2006) cited from Okayo (2013) [4] also reported only a few headteachers used computer in meaningful purposes, therefore, it is a difficult task for headteachers to provide guidance and support for computer and ICT usage in school since computers is considered as new knowledge for them to be learned. Lokman et al (2010) [3] conducted a study based on teachers' perceptions on their headteachers' role as ICT catalyst reported that headteachers' role as supporter and provider for ICT usage and facilities were only at medium level. Based on the findings, it is assumed that headteachers provide least support and inspiration towards the usage of computers in school. Therefore, more exposure of the computer technology should be provided by the local educational authorities. In another study conducted in Nigeria by Unachukwu and Nwankwo (2012) [6], findings revealed that majority of the secondary schools headteachers are not ready for the use of ICT in school administration. It is revealed that only a few headteachers attained much knowledge and skills related to ICT usage and purposes, while quite a number of headteachers having much difficulties and problems in implementing ICT for school administrative purposes.

Conversely, Amara (2006) [16] argued that headteachers competencies of ICT usage were the central determinants of ICT utilisation at school context. However, previous study by Markauskaite (2005) [17] reveal that school headteachers still have low level of competencies in ICT implementation within school leadership paradigm. They believed that headteacher required support and formal training in order to integrate ICT not just for teaching and learning purposes but also in their administrative and decision making tasks [18]. In addition, Witten and Richardson (1991) [33] revealed that only 21 per cent of principals has undergone computer training. As a result, they will face difficulties in facilitating ICT integration. Although previous studies proved that headteachers have least competencies in integration of ICT, Han (2002) [19] disclosed that pre-school leaders have positive attitudes towards the use of ICT and they found ICT was helpful and gave continuous support to the ICT integration at school. In Iran, Mojgan et al [20] revealed that secondary Iranian headteachers used computers frequently in their administrative tasks. High level of computer access, strong perceptions of the attributes of ICT and high level of computer competencies were reported. Another study which also conducted in Kenya, Muthomi, Mbugua and Githua [27] found that headteachers exhibit positive reactions towards the usage of ICT and computer technology in teaching and learning purposes. They also believed that with the inclination of ICT in schools, it will help the students' academic achievements which entails that ICT is a valuable instructional tool that assist the learning and teaching processes. Previous researchers [31, 32] also pointed that as school leaders, they should play their significant role in influencing school community in ICT implementation which has strong impact on students' academic achievement.

Surprisingly, there exist an abundance of studies that measured the ICT engagement among headteachers from various perspectives and educational systems, but little attention was shown to explore the ICT engagement among headteachers during their undergraduate learning process. Most studies that were mentioned typically derived from headteachers who were leading their schools and studies that measured headteachers' belief system, attitudes and dispositions related to ICT while studying in undergraduate learning process is considered as limited [27]. Therefore, this study is an attempt to fill the gap in 
exploring headteachers' ICT engagement within their undergraduate learning stage which was neglected in previous studies.

\section{B. Research Purpose}

The main research purpose of this study is an exploration of essential issues of headteachers' engagement with ICT which involved their perceptions, readiness and ICT literation. Based on the main research purpose, we address the following research questions:

- Are headteachers ICT literate individual?

- What are the perceptions towards the usage of ICT in their learning experiences as an undergraduate student?

- Does headteachers ready to accept ICT in their undergraduates learning experiences and school management tasks?

\section{METHODOLOGY}

\section{A. Design}

The purpose of this study is to explore headteachers' perceptions and readiness in learning computer in their undergraduate studies. Thus, this study aims to gain an indepth exploration and describe the realities of the phenomenon. In addition, qualitative approach would allow subjects more flexibility in expressing their views, without the predetermined responses usually found in quantitative method. As such, the researchers choose descriptive case study design for the research purpose. The case study approach would allow a rich and literal description of the phenomenon being investigated. By using interview, the researcher would be involved directly and gained firsthand information from the participants. This enabled the researcher to have a more holistic interpretation of the phenomenon under study.

\section{B. Participants}

According to Patton (2007) [22], qualitative inquiry focuses in depth on relatively small samples, even single cases, selected purposefully. He recommended specifying a minimum sample size based on expected reasonable coverage of the phenomenon given the purpose of the study; depending on the research problem and research questions to be answered in a study. The sample size could also be constrained by time, money, administrative support and number of resources [23]. As this study was an information-rich case, the researcher employed purposive sampling in selecting the sample. The samples were selected as they could best help the researcher understand the phenomenon that was being investigated [24] and lend credibility to the research study [23]. Researcher selected ten headteachers as it was a reasonable sample size sample [25] from ten primary schools that enrolled their undergraduates' studies in the area of educational administration and leadership in a public university at a part time basis. The selected samples also met the criteria relevant to the research which were important in ensuring authenticity and validity of data collected.

\section{Data collection procedure}

Before conducting the interviews, the researcher approached all ten headteachers and sought their verbal agreement to carry out interviews. Obtaining permission before the start of data collection is a part of the informed consent process as well as an ethical practice [24]. Upon identifying the participants who could best provide an insight to the aim of research study, the researcher contacted potential participant to confirm their willingness to be involved in the study. The researcher obtained consent by asking participants to complete an informed consent form. The consent form detailed the conditions for voluntary participation, anonymity, and confidentiality. Researcher also briefed the participants on the purpose of the interview, the approximate amount of time required for the interview, and how and when the participants may expect to receive results of the study. Next, interviews were conducted and data were collected and transcribe. The researcher then proceeded to analyse the data using the coding process. From the process of coding, themes were identified. After the analysis, findings from the study were reported.

\section{Data analysis}

In this study, a qualitative interview was used as the main data collection approach. After obtaining the interviews data, researcher read and reviewed in order to obtain emerged themes. During the analysis, data were divided into text segments, labeled the segments with codes, examined the codes for overlap and redundancy, and collapsed the codes into broader themes [24]. In the next step, reduction and elimination process was carried out. In this step, researcher determined the invariant constituents and tested each expression for fulfillment of experience requirement, and possibility to abstract and label it. In the final identification of the invariant constituents and themes, the researcher checked the invariant constituents and their accompanying theme against the complete record of the research participants.

\section{E. Validity and trustworthiness}

In qualitative data, validity is addressed through the honesty, depth, richness and scope of data collected. Participants were approached due to the extent of triangulation and objectivity of the researcher [23]. In this study, the researcher addressed interval validity in several ways. All the interviews were audio-taped. The researcher also referred to the participants after transcription to ensure accuracy of interpretation. In determining the trustworthiness, researcher used case study at multi-sites for data collection through the combination of interviewing. To secure credibility, the researcher presented the summary of the findings to the interviewees by e-mail. The researcher then asked the interviewees if they agree with their personal perspectives represented in any or all of the reported findings. To confirm the findings, the researcher asked the participants to comment on the accuracy of verbatim quotes. The researcher further confirmed findings of the study with ICT lecturers from the Institute of Aminnudin Baki (IAB). To further demonstrate the trustworthiness of the interview process, the researcher returned to the starting point of the interview sessions with raw data and reviewed the audio taped interviews. This was to ensure that the final reported findings are rich in information.

\section{FINDINGS}

This study was designed to fulfill the research questions that entail headteachers' perceptions and readiness towards ICT literate as undergraduate students who have enrolled in public universities. Data were presented based 
on themes that emerged during the interviews. The presentation of the data was constructed according to the research objectives. Themes that emerged from the interviews listed were labeled as ICT literation, perception as tool for undergraduate learning and finally their readiness of using ICT.

\section{A. ICT literate}

During the interviews session, headteachers responded that they are considered as ICT literate since ICT is not a new issue to them. In the interviews, it is revealed that most of them utilised their personal computers. They are capable to access and share any information, networking such as e-mail and storing any formal tasks that related to administrations or school operational tasks. Some of them reported that computer is being used to analyse data which they felt is much easier in completing their official and undergraduate learning assignments and tasks. One of the interviewed headteachers mentioned related to the asked question;

...most of us have computer at home. ICT is not something that new to us. Most of us are familiar with computer and ICT. Using computer are much easier and through the usage of computer, we can accessed to any information that related to our undergraduate

Another headteacher also mention the effective usage of ICT and computer in retrieving any data which were relevant for their decision making or implementing any Ministry of Education policies. He further explained;

Basically, I have computer at home and it has multifunction such as retrieving data from the ministry and relevant information meant for my undergraduate studies. I even use computer to access information provided by my lecturers through the e-learning and facebook system. I think, it's much easier for me.

Data revealed that most of the headteachers were ICT literate and they do not face any problem to engage themselves with ICT or computer. One headteachers explained that a computer is a useful device that is able to store any data which were relevant to their undergraduate learning and their school management tasks. He pointed his argument;

ICT benefited my studies and school tasks very much. With the usage of ICT, information can be stored and even disseminated to my friends in short period of time. Using ICT, we also can store any information related to teachers' career paths and promotion, things were much easier now.

One of the headteachers also mentioned that some of his friends which are also headteachers, make use of their ICT competencies in daily management tasks and routines. Some of them use ICT in assessing teachers' performance and achievement. Headteachers also believed that ICT can also be used as an assessment tool. A headteachers further explained his experience;

School leaders should have high competencies using ICT not just meant for undergraduate learning but ICT also can be used as tool for monitoring teachers' competencies and achievement. I believed that with the use of ICT, we simply can predict what will happened and used it as an assessment tool in monitoring our achievement. It is an evidence-based instrument.

Based on the interviews transcript, it is assumed that headteachers are considered as ICT literate since most of them replied that ICT skill is not new to them even they frequently used computer in retrieving knowledge and information for their undergraduate assessment. In addition, they also mention that ICT as a resourceful device for them in fulfilling their undergraduate learning and very helpful in understanding educational policies and official documentations.

\section{B. ICT as tool for headteachers' undergraduate learning experiences as student.}

In exploring headteachers' perceptions related to their usage of ICT in undergraduate learning experiences, we asked question whether ICT is helpful for them especially in their undergraduate learning understandings. During the interview sessions, a few headteachers revealed that he considered ICT as accommodating instrument. One headteacher shared his experience;

. For me, ICT or computer is essential for $21^{\text {st }}$ century learning approach because of it various functions such as devices for communicating. Using a computer, we can easily access to any relevant information even using ICT software, we as school leaders able to check our teachers' daily planning through FrogVLE application even we at our university classroom studying for our undergraduate degree.

From the interviews, headteachers also mentioned that ICT is much beneficial in assisting their administrative and leadership undergraduate learning processes. Most of them agreed that ICT have much impact and influence in their learning process. One of the headteacher revealed, with ICT, their learning process became easier because they can retrieve and even store information using ICT. One headteacher highlighted:

Using ICT, learning process was fast. We easily obtain information using ICT at any location and places even any time that you insist. It also can be used to store your presentations and even any information relevant to your studies. For me, it saves much of my time.

The positive comment above was supported by another headteacher who also believe that ICT gave much positive impact towards their undergraduate learning experiences. She considered ICT as 'informal teacher' in assisting your tasks. During the interview, she explained;

I personally gained much knowledge related to my undergraduate learning tasks. As for me, with the assistance from ICT, it benefited most of my undergraduate task. For instance, I easily obtained any information from reliable online and electronic journals and much easier phase. Using internet, I can simply have examples that related to my assignments and my works now are much systematic and settled at the short period of time.

Another headteacher that was interviewed also underlined the significant positive point that she achieved when using ICT in their undergraduate learning experiences. She believed that ICT teaches and provides her with examples in completing her tasks. She stressed her opinion;

I obtained new knowledge from ICT. I learned how to use ICT with effective manner and even now my presentations and my working papers are much easier to be produce in short period of time.

During the interviews, headteachers stressed that ICT proved them with more opportunity to transfer their knowledge and information whether to other headteachers or their own lecturers. Using ICT, knowledge was dissem- 
inated to their colleagues and submitted within a few minutes. Thus, ICT has facilitated their tasks. He explained his point;

Using ICT, it gives short period of time and easier for us to pass any information to our friends since most of us were from other states and districts. It simply provides us with least time since information will be passed within a few minutes.

In such, it is noticeable that headteachers interviewed have positive reflections towards the usage of ICT in their undergraduate learning. From the interview, headteachers perceived that ICT have much positive impact towards their learning process in obtaining new knowledge, fastened their working process even improving their knowledge related to ICT and even much easier in accessing any related information of educational policies and regulations.

\section{Readiness in accepting ICT}

In exploring their readiness of using ICT which was part of the third objective, headteachers were asked two pertinent items which were addressed: (a) whether they are ready to use computer as their learning tools and (b) do they agree that ICT should be widening its utilisation in the area of headship/principalship study. From the interviews, most of headteachers agreed that ICT should be a part of daily routines of headteachers even when they were school leaders. One of headteachers interviewed mentioned that as school leaders in the $21^{\text {st }}$ Century, they have to engage with ICT due to the recent learning environments which merely assist and use ICT and computer integration in their learning environment. He further explained;

..School leaders nowadays have to expose themselves to ICT since the usage of ICT is essential in our current learning experiences. Therefore, school leaders should be exposed to relevant knowledge that related to ICT since most of learning modes today involved technology integration.

Statement provided by the headteacher was supported by another headteacher who emphasised why school leaders should emphasise on the usage of ICT within school context. She expressed her feeling;

Certainly, I think that I left out of ICT. It moved fast and I think ICT culture at school was neglected since most of us focused on the disciplinary issues. Thus, it is our duty to cultivating ICT culture which recently forgotten.

Conversely, another headteacher also believed that ICT should be part of headship lives and culture since most of headship tasks were technological and electronically based. Thus, she emphasised that as school leaders, they have to master themselves with ICT and technology skills. She further added;

I believe that school head should have knowledge related to ICT and technology since most of school management tasks were electronically based. Everything is computerised, for instance, the usage of espkrus (e-financial). As school leaders for $21^{\text {st }}$ Century, exposure to ICT is a must and we as school leaders should know at least on how to use computer for leadership and management purpose. It is easier to manage school with the assistance of technology.

Even though most of headteachers agreed that ICT knowledge is essential important to them, one headteacher explained that ICT or technology is also lacking in its capacity especially related to administrative and leadership tasks. He strongly believed that ICT have its limitations which also should comprehensively contented by individual and personal monitoring. He emphasised his point;

I do believe that ICT is an essential tool for school leaders to know. However, ICT can't do anything. For instance, monitoring teachers' tasks, we have to be grounded in order to assess the quality of delegated tasks.

To conclude, headteachers are ready to use computer not only meant for their learning, but also in school management and leadership tasks. In terms of exploring whether ICT should be dominant in the headship routines, most of headteachers certainly explained that it is recent requirement for headteachers to have much knowledge related to ICT since most of $21^{\text {st }}$ century learning approach use ICT as part of their learning devices and instrument.

\section{Discussions}

This study is an attempt to explore and investigate whether headteachers who have enrolled their undergraduate studies in educational management and leadership were ICT literate, have positive perceptions on ICT in school and their undergraduate studies. In addition, this study also tries to ascertain whether headteachers who are studying for their undergraduate are ready to use ICT for undergraduate purpose and also in their school leadership tasks. In fulfilling the research objectives, ten headteachers were purposely selected.

Significantly, data were collected through semistructured interviews with ten headteachers and each interview was conducted individually at mutually agreed time and venue to the convenience of the participants. This study employed case study design in collection of data and used qualitative analysis. It provided insights to the ICT literation and headteachers readiness in accepting ICT as their learning and managing tools meant not just for their undergraduate learning experiences but also for school management and human resource purposes. Specific data based on themes were extracted from the interviews that were carried out to provide evidence to ICT literate and readiness that were being investigated.

Empirically, the rapid evolution of ICT and technologies into the educational settings placed upon school leaders to be ICT literate. Thus, headteachers play their significant role as technological leader in school context. As technological leader, headteachers are the most influential individuals in integrating technology and ICT in teaching and learning and even leadership and management of the school. Previous studies indicated that school leaders have many problems and issues related to their ICT competencies, lack of training on ICT and even have negative perceptions towards the ICT into management and administrative tasks. Findings from this study found that ten headteachers that were interviewed were ICT literate. The headteachers were forthright to admit that they have positive remarks towards the usage of ICT and pointed out that as school leaders, they should acquire the relevant knowledge of ICT since technological-based learning is part of $21^{\text {st }}$ Century learning approach. Therefore, school leaders should attain relevant knowledge on ICT pertaining to undergraduate learning and school management 
tasks. Significantly, the findings are in line with the study by Han (2002) [19] who disclosed that school leaders have positive attitudes towards the use of ICT and they also found ICT was helpful and gave continuous support to the ICT integration at school context.

In studying the headteachers' positive remarks towards ICT, most of headteachers seems to agree that ICT gives many benefits to their undergraduate learning experiences and tasks related to school managements. From interviews, most of headteachers highlighted the beneficial aspects of ICT in their undergraduate experiences such as retrieving any data which relevant for their decision making or implementing any Ministry of Education policies; accessing relevant information provided by their lecturers through the e-learning and facebook system; and storing information even disseminated to their friends in short period of time. As for school management tasks, headteachers revealed that they frequently used computer and ICT in assessing teachers' performance and achievement; as an assessment tool in monitoring school's achievement and able predict teachers' career paths and promotions. Comparatively, findings from this study are the opposite to the findings of previous researchers $[4,3$, $6,16,1733$ ] in which headteachers studied have negative perceptions on ICT, low level of support of ICT utilisation, lack of training and expose on ICT.

The second research question entails headteacher perceptions whether ICT is beneficial tools for their undergraduate learning experiences, headteachers revealed that ICT is considered as a helpful and accommodating instrument for them especially in their undergraduate learning experiences. In the interview, headteachers mentioned that they are able to check teachers' daily lesson plan through the usage of ICT even at their undergraduate classroom. In addition, they also explained that their learning process became easier because they can retrieve and even store information using ICT even at any locations or places. In this study, headteachers also emphasised that they can easily obtain any reliable information through online and electronic journals even they manage to get some similar examples from the internet that helps their assignments. We are also being informed that by using ICT in their undergraduate learning experiences, their works are now systematically structured and even able to be completed at the short period of time. This finding concurred with findings from previous researchers $[27,20,19]$ which also found that headteachers exhibit positive reactions towards the usage of ICT and computer technology in teaching and learning purposes. Empirically, headteachers also elucidated that with ICT assisted; they have more opportunity to transfer their knowledge and information whether to other headteachers or their own lecturers. Using ICT, knowledge was disseminated to their colleagues and submitted their assignments within a few minutes even when they at different and far locations and districts.

Finally, this study seeks to investigate headteachers readiness in accepting ICT in their undergraduate learning experiences and school management task. In obtaining reliable data, we interviewed ten headteachers who are currently enrolled as undergraduate students in educational administration and leadership. From the interviews, most of headteachers agreed that ICT should be a part of daily routines of headteachers. One of headteachers interviewed mentioned that as school leaders in the $21^{\text {st }}$ Centu- ry, they have to engage with ICT due to the recent learning environments which merely used ICT and computer integration in their learning environments. Headteachers also pointed out that ICT culture at school is being neglected since most of us focused on the disciplinary issues. Thus, it is our duty to cultivate ICT culture. During interviews, we also asked whether ICT usage should be widening its usage in the area of headship/principalship, they seems to agree that ICT should be part of headship lives and culture since most of headship tasks were technological and electronically based. One headteacher also mentioned that ICT or technology also lacking in its capacity especially related to administrative and leadership tasks. They also strongly believed that ICT has its limitations which also should comprehensively contented by individual and personal monitoring. Lastly, headteachers were ready to use computer not only meant for their learning experiences, but also for their school management and leadership tasks. In terms of exploring whether ICT should be dominant in the headship routines, most of headteachers certainly explained that it is recent requirement for headteachers to have much knowledge related to ICT since most of $21^{\text {st }}$ century learning approach use ICT as part of their learning devices.

In short, findings from this study discovered that headteachers have positive remarks towards the usage of ICT in their undergraduate learning experiences and in their headships routines. The main reasons were ICT able to store, disseminated, and even retrieve any information and able to assist them not just for undergraduate study but also in their managing their schools and teachers development. Finally, this study indicates significant findings that headteachers were positive and believed that they should engage with ICT since most of recent learning models and administrative tasks were now electronically and technologically based. Yet, this research has limitations as it involved a small scope of people and is restricted to the situations in the study area. Thus, this study has sparked many questions where an in-depth investigation needs to be conducted to gain a profound understanding of headteachers' perceptions on ICT.

\section{A. Implications and future study.}

This research illustrates the headteachers' perceptions and readiness related to ICT integration and adoption. Based on the findings, a few suggestions were forwarded for practical and theoretical recommendations. Practical recommendations: (1) based on headteachers' comments, they found that ICT gives much beneficial aspects towards headteacher undergraduate learning experiences and school management task. Thus, we strongly suggested that the Ministry of Education should give more exposure, training and guidance for headteachers since most headteachers felt that ICT helped to improve their undergraduate learning experiences and efficiency in leading and managing the school. Professional development courses and workshops that are related to ICT are able to equip headteachers with skills and knowledge related to ICT which included not just $21^{\text {st }}$ century learning models but also electronically-based school administration approach. For future study that related to headteachers' ICT engagement, further action are required: (1) this study involved only ten headteachers who enrolling as undergraduate in educational management and administration, which needs further replication since a very limited stud- 
ies that exploring headteachers who attending courses or enrolling their undergraduate studies. (2) Secondly, the present study should be undertaken with novice and senior headteachers since this study details the perceptions from senior headteachers. (3) A larger picture of quantitative post-positivism which using a much bigger sample is needed in order to provide generalisations of headteachers' perceptions on ICT.

\section{REFERENCES}

[1] Condie, R., and Munro, B. "The impacts of ICT in schools - a landscape review". Unpublished research report. Coventry: Becta. 2007.

[2] Krishnaveni, R. and Meenakumari, J. "Usage of ICT for information administration in higher education institutions - a study". International Journal of Environmental Science and Development. 1(3), 282 - 286. 2010. http://dx.doi.org/10.7763/IJESD. 2010.V1.55

[3] Lokman Mohd Tahir, Mohd Anuar Abd Rahman, M. AlMuzammil Yassin and Phoon Ai Ling. "Teachers' perceptions towards headteachers' roles as ICT leaders in primary schools", Asia Pacific Journal of Educators and Education, 25, 169-188. 2010.

[4] Okayo, I.O. "Preparedness of the headteachers in the usage of information communication technology in public schools in Bondo district, Kenya". Unpublished Master of Education in Education Administration, University of Nairobi. 2013.

[5] Ong, C.S. and Lay J.Y. "Gender differences in perceptions and relationships among dominants of e-learning acceptance", Computers in Human Behavior, 22 (5), 816-829.2006.

[6] Unachukwu, G., and Nwankwo, C. "Principals' readiness for the use of ICT in school administration in Anambra State of Nigeria", Research Journal in Organizational Psychology \& Educational Studies, 1(2), 114-120. 2012.

[7] Wong, K.P. "School-based technology coordinators and other human factors in the implementation of ICT in primary schools: A comparative study." International Journal of Educational Development Using Information and Communication Technology. 4, 1, $13-26.2008$.

[8] Yushau, B. "Computer attitudes, use, experience, software familiarity and perceived pedagogical usefulness: The case of mathematics professors," Eurasia Journal of Mathematics, Science and Technology Education, 2(3), 91-123. 2006.

[9] Maki, C. "Information and communication technology for administration and management for secondary schools in Cyprus", Journal of Online Learning and Teaching. 4, (3), 18 - 20. 2008.

[10] Krishnaveni, R. \& Meenakumari, J. "Usage of ICT for information administration in higher education institutions - a study." International Journal of Environmental Science and Development. 1(3), $282-286.2010 . \quad$ http://dx.doi.org/10.7763/IJESD. 2010.V1.55

[11] Ong, C.S. and Lay J.Y. "Gender differences in perceptions and relationships among dominants of e-learning acceptance", Computers in Human Behavior, 22 (5): 816-829. 2006. http://dx.doi.org/10.1016/j.chb.2004.03.006

[12] Davies, J.E. 'Assessing and predicting information and communication technology literacy in education undergraduates." Unpublished $\mathrm{PhD}$ thesis. University of Alberta. 2002.

[13] Persaud, B. "School administrators' perspective on their leadership role in technology integration". Unpublished $\mathrm{PhD}$ thesis. Walden University. 2006.

[14] Makhanu, E.S. "Principals' literacy in information and communication technology (ICT): towards improving secondary school performance in Kenya." Unpublished EdD thesis. University of South Africa. 2010.

[15] Kirsch, I. and Lennon, M. "The ICT literacy framework", Measuring Adult Literacy and Life Skills: New Frameworks for Assessment. Ottawa: Statistics Canada. 189-252-MIE, (13). 2005.
[16] Amara S. Census on Computer Literacy of Teachers - November 2006, Sri Lanka Department of Census and Statistics. Accessed Dec 19, 2013 from http://www.statistics.gov.lk. 2006.

[17] Markauskaite, L. Exploring Differences in Trainee Teachers' ICT Literacy: Does Gender Matter? Accessed October 06, 2014 from http://www.ascilite.org.au/confrences/brisbane05/blogs/proceedin gs/51- markauskaite.pdf. 2005.

[18] Pernia, E.E. Strategy framework for promoting ICT literacy in the Asia-Pacific region. Publication of UNESCO Bangkok Communication and information unit. Asia and Pacific Regional Bureau for Education, Bangkok 10110, Thailand. 2008.

[19] Han, C. "Leadership Roles of a Pre-school Principal in the Use of ICT." Contemporary issues in Early Childhood, 3 (2), 293-297. 2002. http://dx.doi.org/10.2304/ciec.2002.3.2.10

[20] Mojgan Afshari, Kamariah Abu Bakar, Wong Su Luan, Marjan Afshari, Foo Say Fooi, and Bahaman Abu Samah. "Computer use by secondary school principals." The Turkish Online Journal of Educational Technology. 9, 3, 8 - 25. 2010.

[21] Maurizio, A and Wilson, J. Policymakers and 21st Century Skills: Partnership for 21st Century Skills. Accessed Nov 14, 2013 from http://thejournal.com/the/printarticle/?id=16878. 2004.

[22] Patton, M. Q. Qualitative Research and Evaluation Methods (2nd ed.). Newbury Park, CA: Sage. 2007.

[23] Cohen, L., Manion, L. and Morrison, K. Research Methods in Education (5th ed.). London: Routledge Falmer. 2000. http://dx.doi.org/10.4324/9780203224342

[24] Cresswell, J. W. Educational Research (4th ed.). Boston: Pearson. 2012.

[25] Smith, J. A., Flowers, P. and Larkin, M. Interpretative Phenomenological Analysis. London: Sage. 2009.

[26] Arumugam Raman, Yahya Don and Abd. Latif Kasim. "The Relationship between Principals' Technology Leadership and Teachers' Technology Use in Malaysian Secondary Schools." Asian Social Science; 10, 18; 30 - 36. 2014.

[27] Muthomi,M.W., Mbugua, Z.K. and Githua, B.N. "Reactions of Schools' Headteacher Toward Computer Use in Teaching and Learning in Secondary Schools in Tharaka-Nithi County in Kenya." International Journal of Information Science and Education. 3, 1, 7 - 14. 2013.

[28] Dinham, S. "Principal leadership for outstanding educational outcomes." Journal of Educational Administration. 43, 4, 338356. 2005. http://dx.doi.org/10.1108/09578230510605405

[29] Walsh, K.. ICT's about learning: School leadership and the effective integration of information and communications technology. Nottingham: National College for School Leadership. 2002

[30] [30] Lokman Mohd Tahir, Mohd Nihra Haruzuan Mohd Said. Khadijah Daud, Mohd Fadzli Ali. "Technological Leadership Support for Knowledge Sharing Purpose: A Case Study." Information.

[31] Flanagan, L., and Jacobsen, M. "Technology leadership for the twenty-first century principal." Journal of Education Administration, 41, 2, 124-143. 2003. http://dx.doi.org/10.1108/0957823 0310464648

[32] Creighton, T. The principal as technology leader. Thousand Oaks, CA: Corwin. 2003.

[33] Witten, D. W., and Richardson, M. D. "Administrative computer use by secondary principals." Journal of Research on Computing in Education, 23(4), 586-587. 1991.

\section{AUTHORS}

Lokman Mohd Tahir, Mohd Fadzli Ali, Mohd Nihra Haruzuan Mohd Said, and Megat Aman Zahiri Megat

Zakaria are with the Faculty of Education, Universiti Teknologi Malaysia (p-lokman@utm.my)

Submitted 24 January 2015. Published as resubmitted by the authors 24 March 2015. 